\title{
Antibiotic therapy and Clostridium difficile infection - primum non nocere - first do no harm
}

\author{
This article was published in the following Dove Press journal: \\ Infection and Drug Resistance \\ 15 September 2015 \\ Number of times this article has been viewed
}

\author{
Grace S Crowther' \\ Mark H Wilcox ${ }^{1,2}$ \\ 'Faculty of Medicine and Health, \\ University of Leeds, Leeds, UK; \\ ${ }^{2}$ Department of Microbiology, Leeds \\ Teaching Hospitals Trust, Leeds, UK
}

Correspondence: Mark H Wilcox Medical Microbiology, Old Medical School, Leeds General Infirmary, Leeds LSI 3EX, UK

Tel +44 II3 3926818

Fax +44 II 33922696

Email mark.wilcox@nhs.net

\begin{abstract}
Treatment options for Clostridium difficile infection (CDI) remain limited despite this usually nosocomial infection posing an urgent threat to public health. A major paradox of the management of CDI is the use of antimicrobial agents to treat infection, which runs the risk of prolonged gut microbiota perturbation and so recurrence of infection. Here, we explore alternative CDI treatment and prevention options currently available or in development. Notably, strategies that aim to reduce the negative effects of antibiotics on gut microbiota offer the potential to alter current antimicrobial stewardship approaches to preventing CDI.
\end{abstract}

Keywords: treatment, prevention, CDI, SYN-004, vaccine, beta-lactams

\section{Introduction}

Over the last three decades, our understanding of the pathophysiology, epidemiology, diagnosis, and treatment of Clostridium difficile infection (CDI) has grown, notably as the incidence and severity of infections have increased dramatically. ${ }^{1}$ From 1935 , when first cultured by Hall and O'Toole, until the 1970s, when its role in antibioticassociated diarrhea and pseudomembranous colitis was elucidated, the $C$. difficile bacterium was believed to be relatively unimportant in clinical significance. ${ }^{2,3}$ The initiation of antibiotic therapy usually leads to perturbation of the intestinal microbiota. Cessation of therapy gradually enables a return to a pretreatment state, a concept called colonization resistance or community resilience. However, this resilience is not necessarily complete, and the resultant patient's intestinal microbiota may remain perturbed for months after antibiotic cessation. ${ }^{4-6} \mathrm{C}$. difficile can exploit the niche created by the effects of antibiotics on the intestinal microbiota, either by the expansion of strain already present before antimicrobial therapy commenced or following the acquisition of a strain while colonization resistance remains perturbed.

The rise to prominence of $C$. difficile as a cause of infective diarrhea was heightened by the emergence of the NAP1/BI/027 strain in the early to mid-2000s and its association with more severe CDI. ${ }^{7}$ The recognition of community-acquired CDI has added another new dimension of concern. ${ }^{8}$ Today $C$. difficile is widely recognized as the leading cause of infective nosocomial diarrhea globally and is associated with significant morbidity and mortality. ${ }^{9-11}$ These facts, coupled with the probability that CDI might be substantially underdiagnosed in some settings, serve to support its designation by the CDC as an urgent public health threat. ${ }^{12-14}$

The resident microbiota of the gastrointestinal tract plays a crucial role in protecting against invading pathogenic microorganisms via colonization resistance. ${ }^{15,16}$ Any exposure to an antibiotic is a major risk factor for the development of CDI; enhanced 
CDI risk has been shown to persist for up to 3 months postexposure. ${ }^{17,18}$ This is particularly true with clindamycin, the penicillins ampicillin or amoxicillin, cephalosporins, and fluoroquinolones. ${ }^{19-22}$ In an effort to minimize exposure to these selected classes of drugs, interventions have been made to substitute one class (eg, a ureidopenicillin) for another (eg, an oxyimino-cephalosporin) in an attempt to reduce rates of CDI. ${ }^{20}$ Additionally, there is evidence that the class of drug is not the only parameter to consider when selecting a particular agent. Another important determinant of CDI risk is the cumulative antibiotic exposure as measured by length of therapy and number of different antibiotics used, either simultaneously or sequentially. ${ }^{23}$

As stated in the Infectious Disease Society of America/ Society for Healthcare Epidemiology of America (IDSA/ SHEA) guidelines for developing an institutional program to enhance antibiotic stewardship, "The primary goal of antimicrobial stewardship is to optimize clinical outcomes while minimizing unintended consequences of antimicrobial use, including toxicity, the selection of pathogenic organisms (such as C. difficile), and the emergence of resistance". ${ }^{24}$ As previously stated, the use of broad-spectrum (workhorse) antimicrobials such as penicillins, cephalosporins, and fluoroquinolones as empiric agents is associated with subsequent CDI development. This concept is sometimes referred to as "collateral damage". Ideally, the use of these higher CDI risk antimicrobial classes should be minimized or avoided entirely, but this is not always practical. Furthermore, restriction of whole antibiotic classes will likely lead to less diversity of antimicrobial prescribing, which is associated with increased risk of resistance. ${ }^{25,26}$ Notably, however, the collateral damage caused by antibiotic use may be more serious than the original infection. Furthermore, many patients, particularly the elderly with multiple comorbidities, are recipients of antibiotic polypharmacy, possibly starting in the community setting and then continuing after hospitalization.

Should CDI occur, the first step in treatment is the discontinuation of all antibiotics, if possible. This is usually impractical, especially in patients with serious and/or multiple comorbidities. ${ }^{27-29}$ The 2014 European Society of Clinical Microbiology and Infectious Diseases (ESCMID) guidelines recommend metronidazole as initial therapy for mild-to-moderate CDI, with oral vancomycin reserved for more severe cases (Table 1). ${ }^{30}$ However, recently published data show that vancomycin was superior to metronidazole in achieving clinical success for all patients in a combined Phase III database. ${ }^{31}$ For severe, complicated cases of CDI, oral vancomycin, with or without IV metronidazole, plus
Table I Therapeutic regimens for CDI

\begin{tabular}{ll}
\hline First-line option & Second-line option \\
\hline $\begin{array}{l}\text { Nonsevere CDI } \\
\text { Metronidazole (500 mg TID I0 days)* }\end{array}$ & $\begin{array}{l}\text { Vancomycin (I25 mg QID I0 days) } \\
\text { Fidaxomicin (200 mg BID I0 days) }\end{array}$ \\
$\begin{array}{l}\text { Severe CDI } \\
\text { Vancomycin }\end{array}$ & Fidaxomicin (200 mg BID I0 days)** \\
$($ I $25 \mathrm{mg}$ QID I0 days)* & \\
First recurrence & \\
Vancomycin (I25 mg QID I0 days)** & Metronidazole (500 mg TID \\
Fidaxomicin (200 mg BID I0 days)** & I0 days) ${ }^{* * *}$ \\
\hline
\end{tabular}

Notes: For information on rates of recurrence for each therapeutic regimen, please refer ESCMID guidelines. *Indicates strong support for recommendation of use; **Indicates moderate support for recommendation of use; ****ndicates marginal support for recommendation of use. Data from Debast et al..$^{30}$

Abbreviations: CDI, Clostridium difficile infection; TID, three times daily; QID, four times a day; BID, twice daily.

a vancomycin retention enema if ilius is present is recommended (Table 1).

Fidaxomicin was approved by the FDA in 2012 for the treatment of $C$. difficile-associated diarrhea in adults ( $\geq 18$ years of age). Fidaxomicin is a narrow-spectrum agent with minimal systemic absorption when administered orally, possesses low activity against normal gut microbiota, and is active against $C$. difficile, most strains of staphylococci, and enterococci. ${ }^{32,33}$ Fidaxomicin has been shown to be noninferior to vancomycin for initial cure in patients with CDI and was associated with a lower recurrence rate and superior sustained clinical response. ${ }^{34,35}$ Adverse event rates were similar; overall, $5.9 \%$ of patients on fidaxomicin and $6.9 \%$ on vancomycin withdrew from trials as a result of adverse events. Fidaxomicin was demonstrated to be superior to vancomycin in patients with non-NAP1/BI/027 strains. ${ }^{36}$ In the United Kingdom, use of fidaxomicin should be considered in patients with severe CDI who are considered at high risk of recurrence or not responding to vancomycin therapy. It is also the recommended option for patients with a first recurrence of CDI (Table 1). ${ }^{37}$ Use of fidaxomicin, however, has remained limited due to its high price, a negative attribute further exacerbated by the recent availability of a generic version of oral vancomycin in the United States. ${ }^{38}$

It is important to note that current standards of care for CDI (metronidazole, vancomycin, or fidaxomicin) are associated with at least $12 \%-20 \%$ levels of recurrence, with further recurrences more likely in those who require follow-up treatment. ${ }^{39}$ High gut concentrations of conventional CDI therapeutic agents can adversely affect the microbiota, leading to secondary infections (relapses and reinfections) of CDI and selection of other potential pathogens, such as enterococci. ${ }^{40}$

Our approach to CDI management needs to be multifactorial and incorporate improved diagnostics, epidemiology, 
infection control, antibiotic stewardship, and prevention and treatment options. Currently, there are multiple antimicrobial agents (eg, cadazolid [Actelion], surotomycin [Cubist], SMT19969 [Summit Corporation], and CR3123 [Crestone]) in various stages of development for the treatment of CDI. ${ }^{39,41}$ In addition to this traditional CDI management strategy, several different approaches to the prevention and treatment of CDI that do not utilize antibiotic agents to treat established infections are in development (Table 2). Although all differ from each other on a mechanistic level, most are grounded on the principle of attempting to spare, protect, or repair the endogenous gut flora. ${ }^{42}$

The microbiological supplementation approach, notably fecal microbiota transplant and Rebiotix oral preparation (Table 2), addresses the high rates of recurrence and particularly the debilitating impact of multiple recurrences following treatment with either vancomycin or metronidazole by attempting to restore the "normal" gut flora. With the exception of VP20621, none of the approaches listed are aimed at preventing the initial episode of CDI. Additionally, because

Table 2 Alternative Clostridium difficile infection preventative and therapeutic approaches

\begin{tabular}{|c|c|c|}
\hline Approach & Product & $\begin{array}{l}\text { Development } \\
\text { stage }\end{array}$ \\
\hline \multirow[t]{4}{*}{ Microbiological } & $\begin{array}{l}\text { - Microbiota supplementation } \\
\text { (fecal microbiota transplant) }\end{array}$ & $\mathrm{n} / \mathrm{a}$ \\
\hline & $\begin{array}{l}\text { - RBX2660 (Rebiotix; an oral } \\
\text { preparation of live microbes) }\end{array}$ & Phase II \\
\hline & $\begin{array}{l}\text { - SER I09 (SeresHealth; } \\
\text { an orally delivered } \\
\text { combination of spores) }\end{array}$ & Phase I/II \\
\hline & $\begin{array}{l}\text { - VP2062I (Shire [formerly } \\
\text { ViroPharma]; spores of NTCD } \\
\text { strain M3) }\end{array}$ & Phase II \\
\hline \multirow[t]{4}{*}{$\begin{array}{l}\text { Nonmicrobial } \\
\text { biological }\end{array}$} & $\begin{array}{l}\text { - Passive immunization } \\
\text { (MK34I5A [Merck]) } \\
\text { - Vaccines: }\end{array}$ & Phase III \\
\hline & C. diffense (Sanofi Pasteur) & Phase III \\
\hline & PF-06425090 (Pfizer) & Phase II \\
\hline & IC84 (Valneva) & Phase I \\
\hline \multirow[t]{2}{*}{$\begin{array}{l}\text { Antibiotic } \\
\text { inactivation }\end{array}$} & $\begin{array}{l}\text { SYN-004 (Synthetic Biologics; } \\
\text { a synthetic Class A } \beta \text {-lactamase } \\
\text { enzyme for use with IV } \\
\text { cephalosporins [including } \\
\text { ceftriaxone] and penicillins) }\end{array}$ & Phase II \\
\hline & $\begin{array}{l}\text { DAVI } 32 \text { (DaVolterra; a } \\
\text { medical device consisting } \\
\text { of an activated-charcoal- } \\
\text { based product in an enteric- } \\
\text { coated pill) }\end{array}$ & Phase I \\
\hline
\end{tabular}

Note: Adapted from Drug Discovery Today, Volume 20, Ivarsson ME, Leroux J, Castagner B, Investigational new treatments for Clostridium difficile infection, Pages 602-608, Copyright 2015, with permission from Elsevier. ${ }^{39}$

Abbreviations: $\mathrm{n} / \mathrm{a}$, not available; NTCD, nontoxigenic Clostridium difficile. the infective process can still be active and the need for antibiotic cover still exists, these strategies are primarily aimed at present for the treatment of CDI recurrence. Furthermore, the administration of antibiotics could obviate such therapies, as this would reinterrupt the gut microbiota.

The nonmicrobial biological approach (Table 2) encompasses passive immunization and vaccination and target the toxins produced by the $C$. difficile bacterium. Monoclonal antibodies given in addition to either metronidazole or vancomycin were superior to standard treatment alone for the prevention of recurrence in a Phase II study; Phase III studies are nearing completion. ${ }^{43}$ The therapy with this adjuvant antibody did not, however, improve the severity of illness, the length of hospitalization, or the time to resolution of diarrhea.

There are multiple key issues to be addressed for the development of an effective vaccine for CDI, including antigen(s) selection, delivery system, patient selection, and immunoresponsiveness, particularly in the elderly. ${ }^{44,45}$ In addition, the requirement for multiple doses of vaccine impacts negatively on the development and success of a toxoid vaccine. ${ }^{46}$ Additionally, current vaccines do not inhibit colonization by $C$. difficile. ${ }^{39}$

The third approach, antibiotic inactivation (Table 2), is targeted at eliminating the collateral damage associated with the initial antibiotic exposure, thereby potentially reducing the risk of CDI. ${ }^{39}$ As antibiotics are often necessary, the coadministration of an agent such as SYN-004 can inactivate the antibiotic in the large intestine, thereby allowing the systemic distribution of the active agent but avoiding the damage associated with the antibiotic to the intestinal microbiota, thereby preventing CDI. As such, the antibiotic inactivation approach is a novel strategy that could not only prevent the initial episode of CDI but also allow the continued use of broad-spectrum penicillins and cephalosporins, which are widely prescribed for empiric treatment of serious infections.

Recently, there was a call by Gerding and Johnson for "inside the box" and "outside the box" thinking in treating CDI. 47 "Inside the box" agents include vancomycin, metronidazole, fidaxomicin, and the other agents previously listed that are to be used to treat CDI. "Outside the box" approaches to CDI treatment and prevention include the microbiological, nonmicrobiological, and antibiotic inactivation approaches discussed earlier. These avoid "the continued suppression of normal bacterial microbiota that occurs with antimicrobial management". ${ }^{47}$

In closing, our understanding of the importance of C. difficile has been transformed in the three decades since its discovery as a human pathogen; it is now considered to 
be an urgent public health threat. CDI is closely associated with the use of antibiotics. As such, a key negative impact of CDI is the ability to continue to safely prescribe particular antibiotics, notably penicillins and cephalosporins, which have long been considered to be valuable classes for treating serious infections. Using an antibiotic inactivation approach can both potentially reduce the risk of collateral damage and CDI and allow the continued clinical use of valuable antibiotics. This approach could provide reassurance that, even in patients at increased risk of CDI, antibiotic therapy can be initiated and continued to achieve optimal clinical outcomes. The development of microbiome-friendly interventions could also be beneficial in preventing the establishment and selection of other multidrug-resistant organisms that exploit the niches created by antibiotic-induced collateral damage.

\section{Funding}

This perspective was sponsored by an educational grant from Synthetic Biologics (Rockville, MD, USA). Perihelion Medical Communications also received compensation fees from Synthetic Biologics for services with regards to manuscript preparation.

\section{Disclosure}

GC has received financial support to attend meetings from Novacta Biosystems and Astellas. MW has received consulting fees from Abbott Laboratories, Actelion, Astellas, Astra-Zeneca, Bayer, Cerexa, Cubist, Durata, The European Tissue Symposium, The Medicines Company, MedImmune, Merck, Motif Biosciences, Nabriva, Optimer, Paratek, Pfizer, Roche, Sanofi-Pasteur, Seres, Summit, and Synthetic Biologics; lecture fees from Abbott, Alere, Astellas, Astra-Zeneca, and Pfizer; and grant support from Abbott, Actelion, Astellas, bioMerieux, Cubist, Da Volterra, The European Tissue Symposium, Merck, and Summit. The authors report no other conflicts of interest in this work.

\section{References}

1. Reveles KR, Lee GC, Boyd NK, Frei CR. The rise in Clostridium difficile infection incidence among hospitalized adults in the United States: 2001-2010. Am J Infect Control. 2014;42(10):1028-1032.

2. Hall IC, O'Toole E. Intestinal flora in new-born infants: with a description of a new pathogenic anaerobe, Bacillus difficilis. Am J Dis Child. 1935;49:390-402.

3. Bartlett JG. Clostridium difficile: history of its role as an enteric pathogen and the current state of knowledge about the organism. Clin Infect Dis. 1994;18(Suppl 4):S265-S272.
4. Dethlefsen L, Huse S, Sogin ML, Relman DA. The pervasive effects of an antibiotic on the human gut microbiota, as revealed by deep $16 \mathrm{~S}$ rRNA sequencing. PLoS Biol. 2008;6(11):e280.

5. Dethlefsen L, Relman DA. Incomplete recovery and individualized responses of the human distal gut microbiota to repeated antibiotic perturbation. Proc Natl Acad Sci U S A. 2011;108(Suppl 1): $4554-4561$.

6. Jakobsson HE, Jernberg C, Andersson AF, Sjolund-Karlsson M, Jansson JK, Engstrand L. Short-term antibiotic treatment has differing long-term impacts on the human throat and gut microbiome. PLoS One. 2010;5(3):e9836.

7. Freeman J, Bauer MP, Baines SD, et al. The changing epidemiology of Clostridium difficile infections. Clin Microbiol Rev. 2010;23(3): 529-549.

8. Gupta A, Khanna S. Community-acquired Clostridium difficile infection: an increasing public health threat. Infect Drug Resist. 2014;7:63-72.

9. Peery AF, Dellon ES, Lund J, et al. Burden of gastrointestinal disease in the United States: 2012 update. Gastroenterology. 2012;143(5): e1171-e1173.

10. Wiegand PN, Nathwani D, Wilcox MH, Stephens J, Shelbaya A, Haider S. Clinical and economic burden of Clostridium difficile infection in Europe: a systematic review of healthcare-facility-acquired infection. J Hosp Infect. 2012;81(1):1-14.

11. Chitnis AS, Holzbauer SM, Belflower RM, et al. Epidemiology of community-associated Clostridium difficile infection, 2009 through 2011. JAMA Intern Med. 2013;173(14):1359-1367.

12. Kuntz JL, Polgreen PM. The importance of considering different healthcare settings when estimating the burden of Clostridium difficile. Clin Infect Dis. 2014;60(6):831-836.

13. Davies KA, Longshaw CM, Davis GL, et al. Underdiagnosis of Clostridium difficile across Europe: the European, multicentre, prospective, biannual, point-prevalence study of Clostridium difficile infection in hospitalised patients with diarrhoea (EUCLID). Lancet Infect Dis. 2014; 14(12):1208-1219.

14. Centers for Disease Control and Prevention. Antibiotic Resistance Threats in the United States, 2013. Available from: http://www.cdc. gov/drugresistance/threat-report-2013/pdf/ar-threats-2013-508.pdf. Accessed December 26, 2014.

15. Clasener HA, Vollaard EJ, van Saene HK. Long-term prophylaxis of infection by selective decontamination in leukopenia and in mechanical ventilation. Rev Infect Dis. 1987;9(2):295-328.

16. Vollaard EJ, Clasener HA. Colonization resistance. Antimicrob Agents Chemother. 1994;38(3):409-414.

17. Monaghan TM. New perspectives in Clostridium difficile disease pathogenesis. Infect Dis Clin North Am. 2015;29(1):1-11.

18. Hensgens MP, Goorhuis A, Dekkers OM, Kuijper EJ. Time interval of increased risk for Clostridium difficile infection after exposure to antibiotics. J Antimicrob Chemother. 2012;67(3):742-748.

19. Baxter R, Ray GT, Fireman BH. Case-control study of antibiotic use and subsequent Clostridium difficile-associated diarrhea in hospitalized patients. Infect Control Hosp Epidemiol. 2008;29(1):44-50.

20. Settle CD, Wilcox MH, Fawley WN, Corrado OJ, Hawkey PM. Prospective study of the risk of Clostridium difficile diarrhoea in elderly patients following treatment with cefotaxime or piperacillin-tazobactam. Aliment Pharmacol Ther. 1998;12(12):1217-1223.

21. Wilcox MH, Shetty N, Fawley WN, et al. Changing epidemiology of Clostridium difficile infection following the introduction of a national ribotyping-based surveillance scheme in England. Clin Infect Dis. 2012;55(8):1056-1063.

22. Wilcox MH, Freeman J, Fawley W, et al. Long-term surveillance of cefotaxime and piperacillin-tazobactam prescribing and incidence of Clostridium difficile diarrhoea. J Antimicrob Chemother. 2004;54(1): 168-172.

23. Stevens V, Dumyati G, Fine LS, Fisher SG, van Wijngaarden E. Cumulative antibiotic exposures over time and the risk of Clostridium difficile infection. Clin Infect Dis. 2011;53(1):42-48. 
24. Dellit TH, Owens RC, McGowan JE Jr, Infectious Diseases Society of America; Society for Healthcare Epidemiology of America, et al. Infectious Diseases Society of America and the Society for Healthcare Epidemiology of America guidelines for developing an institutional program to enhance antimicrobial stewardship. Clin Infect Dis. 2007;44(2):159-177.

25. Sandiumenge A, Diaz E, Rodriguez A, et al. Impact of diversity of antibiotic use on the development of antimicrobial resistance. JAntimicrob Chemother. 2006;57(6):1197-1204.

26. Abel zur Wiesch P, Kouyos R, Abel S, Viechtbauer W, Bonhoeffer S. Cycling empirical antibiotic therapy in hospitals: meta-analysis and models. PLoS Pathog. 2014;10(6):e1004225.

27. Alonso CD, Treadway SB, Hanna DB, et al. Epidemiology and outcomes of Clostridium difficile infections in hematopoietic stem cell transplant recipients. Clin Infect Dis. 2012;54(8):1053-1063.

28. Alonso CD, Marr KA. Clostridium difficile infection among hematopoietic stem cell transplant recipients: beyond colitis. Curr Opin Infect Dis. 2013;26(4):326-331.

29. Neofytos D, Kobayashi K, Alonso CD, et al. Epidemiology, risk factors, and outcomes of Clostridium difficile infection in kidney transplant recipients. Trans Infect Dis. 2013;15(2):134-141.

30. Debast SB, Bauer MP, Kuijper EJ, European Society of Clinical Microbiology and Infectious Diseases. European Society of Clinical Microbiology and Infectious Diseases: update of the treatment guidance document for Clostridium difficile infection. Clin Microbiol Infect. 2014;20(Suppl 2):1-26.

31. Johnson S, Louie TJ, Gerding DN, Polymer Alternative for CDI Treatment (PACT) investigators, et al. Vancomycin, metronidazole, or tolevamer for Clostridium difficile infection: results from two multinational, randomized, controlled trials. Clin Infect Dis. 2014;59(3):345-354.

32. Venugopal AA, Johnson S. Fidaxomicin: a novel macrocyclic antibiotic approved for treatment of Clostridium difficile infection. Clin Infect Dis. 2012;54(4):568-574.

33. Sears P, Ichikawa Y, Ruiz N, Gorbach S. Advances in the treatment of Clostridium difficile with fidaxomicin: a narrow spectrum antibiotic. Ann N Y Acad Sci. 2013;1291:33-41.

34. Louie TJ, Miller MA, Mullane KM, OPT-80-003 Clinical Study Group, et al. Fidaxomicin versus vancomycin for Clostridium difficile infection. N Engl J Med. 2011;364(5):422-431.

35. Cornely OA, Crook DW, Esposito R, OPT-80-004 Clinical Study Group, et al. Fidaxomicin versus vancomycin for infection with Clostridium difficile in Europe, Canada, and the USA: a double-blind, non-inferiority, randomised controlled trial. Lancet. 2012;12(4):281-289.
36. Crook DW, Walker AS, Kean Y, Study 003/004 Teams, et al. Fidaxomicin versus vancomycin for Clostridium difficile infection: meta-analysis of pivotal randomized controlled trials. Clin Infect Dis. 2012;55 (Suppl 2):S93-S103.

37. Wilcox MH, Hawkey PM, Patel B, Planche T, Stone S. Updated guidance on the management and treatment of Clostridium difficile infection; 2015. Available from: https://www.gov.uk/ government/uploads/system/uploads/attachment_data/file/321891/ Clostridium_difficile_management_and_treatment.pdf. 2013 Accessed January 17, 2015.

38. Surawicz CM, Brandt LJ, Binion DG, et al. Guidelines for diagnosis, treatment, and prevention of Clostridium difficile infections. Am J Gastroenterol. 2013;108(4):478-498. [quiz 499].

39. Ivarsson ME, Leroux J, Castagner B. Investigational new treatments for Clostridium difficile infection. Drug Discov Today. 2015;20: 602-608.

40. Tarkkanen AM, Heinonen T, Jõgi R, et al. P1A recombinant betalactamase prevents emergence of antimicrobial resistance in gut microflora of healthy subjects during intravenous administration of ampicillin. Antimicrob Agents Chemother. 2009;53(6):2455-2462.

41. Bhansali SG, Mullane K, Ting LS, Leeds J, Dabovic K, Praestgaard J. Pharmacokinetics of LFF571 and vancomycin in patients with moderate Clostridium difficile infections. Antimicrob Agents Chemother. 2014;59:19.

42. Chang JY, Antonopoulos DA, Kalra A, et al. Decreased diversity of the fecal microbiome in recurrent Clostridium difficile-associated diarrhea. J Infect Dis. 2008;197(3):435-438.

43. Lowy I, Molrine DC, Leav BA, et al. Treatment with monoclonal antibodies against Clostridium difficile toxins. N Engl J Med. 2010; 362(3):197-205.

44. Safdar A. Treatment with monoclonal antibodies against Clostridium difficile toxins. N Engl J Med. 2010;362(15):1444-1445. [author reply 1445-1446].

45. Gens KD, Elshaboury RH, Holt JS. Fecal microbiota transplantation and emerging treatments for Clostridium difficile infection. J Pharm Prac. 2013;26(5):498-505.

46. Zhao S, Ghose-Paul C, Zhang K, Tzipori S, Sun X. Immune-based treatment and prevention of Clostridium difficile infection. Hum Vaccin Immunother. 2014;10(12):3522-3530.

47. Gerding DN, Johnson S. Management of Clostridium difficile infection: thinking inside and outside the box. Clin Infect Dis. 2010;51(11): 1306-1313.
Infection and Drug Resistance

\section{Publish your work in this journal}

Infection and Drug Resistance is an international, peer-reviewed openaccess journal that focuses on the optimal treatment of infection (bacterial, fungal and viral) and the development and institution of preventive strategies to minimize the development and spread of resistance. The journal is specifically concerned with the epidemiology of antibiotic

\section{Dovepress}

resistance and the mechanisms of resistance development and diffusion in both hospitals and the community. The manuscript management system is completely online and includes a very quick and fair peerreview system, which is all easy to use. Visit http://www.dovepress.com/ testimonials.php to read real quotes from published authors. 